\title{
A alfabetização e o dialogismo: encontros com a palavra na vida
}

\author{
Maria Aparecida Lapa de Aguiar* \\ Nelita Bortolotto** \\ Nilcéa Lemos Pelandré***
}

\section{Resumo}

Neste trabalho procura-se contextualizar a importância para a alfabetização da concepção dialógica da linguagem - da arquitetônica de Bakhtin -, e da perspectiva de aprendizagem de Vigotski, buscando contribuir com discussóes que se póem desde a década de 1980 sobre o assunto, estendendo-se aos dias atuais. Para tal intento, são apresentadas, em linhas gerais, as orientaçôes dos documentos oficiais no que diz respeito às concepçôes de linguagem e às propostas teórico-metodológicas em uma perspectiva de letramento e de interaçáo social. Também se faz a defesa da alfabetização pela abordagem histórico-cultural e de práticas sociais de leitura e escrita constituídas na relação eu/outro. Discutem-se, ainda, algumas possibilidades metodológicas desenvolvidas com base em projetos de docência que possam edificar o processo alfabetizador pela atividade da comunicaçáo verbal, ou seja, pela palavra real como enunciado concreto. Por fim, defende-se a consolidaçáa de uma metodologia da alfabetização que propicie o desenvolvimento de práticas sociais no decorrer do processo de apropriação do sistema de escrita, ao mesmo tempo em que conduza à valoração do sujeito com responsabilidade sobre o pensar, falar e atuar. Preconizase assim o reforço de políticas públicas de formação em serviço de professores, fomentando atitudes responsivas perante os sujeitos-alunos, constituindo-os leitores e escritores competentes.

Palavras-chave: Alfabetização. Interação verbal. Formação docente.

* Doutora em Educação pela Universidade Federal de Santa Catarina (UFSC). Professora Departamento de Estudos Especializados em Educação da Universidade Federal de Santa Catarina (UFSC).

** Doutora em Educação pela Universidade Federal de Santa Catarina (UFSC). Professora do Departamento de Metodologia de Ensino e da Pós-graduação em Educação da Universidade Federal de Santa Catarina (UFSC).

*** Doutora em Linguística pela Universidade Federal de Santa Catarina (UFSC). Professora voluntária da Universidade Federal de Santa Catarina (UFSC). 


\section{Introdução}

Vivemos um momento de ênfase em políticas públicas voltadas à formação do professor alfabetizador. Alguns programas como o Pró-letramento (2008) e, mais recentemente, o Pacto Nacional pela Alfabetização na Idade Certa (PNAIC) $^{1}$ (2012) vêm discutindo concepçôes e perspectivas metodológicas que facultem ao aluno a apropriação do sistema de escrita por meio de práticas sociais de leitura e escrita e lhe permita saber não apenas na escola e para a escola, mas, sobretudo, para fora dela entretecendo mundos da vida e da cultura.

Soares (2004) acura a nossa reflexão sobre o ato da alfabetização provocando-nos a pensar sobre a trajetória histórica de constituição dessa prática social, algo que poderia nos levar à compreensão aprofundada de linhas de pensamento, às vezes congruentes entre si, às vezes conflitantes. Na década de 1980, expóe a autora, acirram-se as críticas a métodos de alfabetização nominados, à época, de tradicionais (os chamados métodos sintéticos, analíticos e mistos), ao mesmo tempo em que há a emergência do termo "letramento", não excetuado de crítica e de definiçóes nem sempre consonantes ${ }^{2}$.

A compreensão de conceitos como de Letramento e de Alfabetização ou da relação destes entre si é tema que ainda requer debate, requer o questionamento em torno de certas linhas de pensamento, pois necessitamos nos fundamentar em conceitos, concepçóes e metodologias que conduzam à aprendizagem da leitura e da escrita em harmonia com as exigências da vida cotidiana e da cultura (mundo da cognição - conhecimento -, estética, ética) diferindo da defesa de uma alfabetização cujo foco direcionava-se apenas à relação fonema-grafema, tônica dos métodos de alfabetização que faziam (fazem?) parte da tradição histórica da escola. Se é certo que por tais métodos a alfabetização ocorria, é certo também que estes se fundamentavam na ideia de que as crianças ao conseguirem entender a relação fonema-grafema e vice-versa, estariam aptas a lidar com a linguagem escrita e leitura em toda a sua complexidade (escrever e falar - práticas discursivas; relaçôes humanas; alteridade; valores; crenças; ritos etc.), ou seja, com o compromisso social de comprometimento com a palavra minha e a do outro, enfim, com a interação humana.

Particularmente, neste artigo, em um primeiro momento, pretendemos apresentar em linhas gerais o que os documentos oficiais - Proposta Curricular de Santa Catarina (1998); Proposta Curricular de Santa Catarina: Estudos Temáticos (2005); Parâmetros Curriculares Nacionais (PCN) (BRASIL, 2001), 
Pacto Nacional pela Alfabetização na Idade Certa (BRASIL, 2012) e Orientações para o Ensino Fundamental de nove anos (BRASIL, 2007) - vêm abordando em relação à defesa de uma concepção de linguagem como interação humana, que requer um processo de sistematização de conhecimentos atrelados a uma metodologia de ensino que possa contemplar a apropriação do sistema de escrita em uma perspectiva de letramento, de interação social.

Em um segundo momento, reafirmamos nossa defesa da alfabetização pela abordagem histórico-cultural com base na discussão de possibilidades metodológicas para a alfabetização que concedam prioridade a práticas sociais de leitura e escrita constituídas na relação eu/outro. Como afirma Bakhtin (2003, p. 311, grifos do autor), "O acontecimento da vida do texto, isto é, a sua verdadeira essência, sempre se desenvolve na fronteira de duas consciências, de dois sujeitos". O texto (texto enunciado) constituído, portanto, na relaçáo eu/outro é atividade humana e, como tal, decorre de um projeto do dizer (projeto discursivo), da realização desse projeto, operado mediante um sistema de linguagem. Não o seu inverso! Enfatiza ainda o autor: "Quando o enunciado é tomado para fins de análise linguística, sua natureza dialógica é repensada, é tomada no sistema da língua (como sua realização) e não no grande diálogo da comunicação discursiva” (BAKHTIN, 2003, p. 324). Portanto, nossa forma de olhar o mundo, a nós mesmos e o outro no mundo é pela compreensão dos processos e produtos da interação de indivíduos socialmente organizados (BAKHTIN [VOLOCHÍNOV], 1990).

\section{O ensino de língua portuguesa nos anos iniciais: possibilidades metodológicas pela abordagem histórico- cultural}

Desde a década de 1980, em um período que se caracterizou fortemente pelos processos de democratização da escola pública, vem-se defendendo no âmbito da formação de professores (inicial ou continuada), a concepção de linguagem como interação humana e, por consequência, discutem-se metodologias de ensino que possam ir ao encontro dessa concepção. Nessa perspectiva, algumas iniciativas materializaram-se em Propostas Curriculares estaduais e municipais e em Parâmetros Curriculares Nacionais.

No que diz respeito à Proposta Curricular do Estado de Santa Catarina (PCSC) (SANTA CATARINA, 1998) e aos PCN (BRASIL, 2001), em ambos 
os documentos projeta-se, por uma abordagem histórico-cultural, a voz de autores como Bakhtin e partícipes do seu Círculo, que punham em evidência o dialogismo das relaçóes discursivas, assim como de Vigotski e discípulos (Lúria, Leontiev, entre outros) com sua psicologia histórico-social. De certo modo, tanto a PCSC quanto os PCN tentavam dar conta da afirmação do ensino da leitura e da escrita (letramento/multiletramentos) dimensionados pela compreensão de língua e linguagens no acontecimento da vida (na atividade humana). Em termos de metodologia de estudos da linguagem, nessa década de 1980, a crítica à escola era contumaz: a escola náo conseguia atingir todo o seu público com um ensino de qualidade por razóes inúmeras, dentre elas, as escolhas que fazia em relação às abordagens teóricas e aos métodos, cujas consequências faziam-se sentir nos alarmantes números de evasão e repetência evidenciados em pesquisas acadêmico-científicas, sem contar com o baixo nível de conhecimento apresentado ao término do ensino fundamental por aqueles que conseguiam permanecer na escola.

É importante também ressaltar que a objetivação na prática docente de uma proposta curricular nem sempre causa os efeitos desejados, por uma série de variáveis, como por exemplo, a falta de uma formação continuada que possa oferecer a todos a possibilidade de discussão constante de suas premissas ${ }^{3}$. O PCSC da década de 1990 já defendia: "A alfabetização constitui-se numa atividade interativa, interdiscursiva de apropriação de diferentes linguagens produzidas culturalmente. Dentre elas situa-se a escrita como um artefato presente em todas as atividades das sociedades letradas" (SANTA CATARINA, 1998, p. 35).

$\mathrm{O}$ que essa Proposta, em específico, sugere em relação à alfabetização é um olhar e uma atitude diferenciada no que diz respeito ao ensino em nossas escolas, para que sejam incorporadas metodologias que contemplem distintas possibilidades de trabalho com a linguagem, não desconsiderando o percurso constituído ao longo da história da humanidade. Assim, considera a linguagem escrita - patrimônio cultural da humanidade - como um importante instrumento para que se tenha acesso a conhecimentos diversos, apontando para uma concepçáo de linguagem como interação humana, pela possibilidade do encontro de vozes.

A proposta enfatiza, no processo de escolarização, a necessária vivência das crianças desde muito cedo com as diversas possibilidades de trabalho com gêneros do discurso instituídos nas várias esferas sociais (política, jurídica, religiosa, educacional, familiar, jornalística etc.): 
Metodologicamente, isto significa que a escola deve intensificar, no interior da sala de aula, a interaçáo com as produçôes gráficas utilizadas no meio cultural. Produçóes que possuem funçóes específicas conforme o contexto social em que foram produzidas - função de registro, divulgação de informaçóes e conhecimentos, lazer, comunicação, identificação, expressão de sentimentos e vivências. A interação com tais produções, e suas funções permite que a criança perceba a importância da escrita na relação com os outros, tornando-a necessária (SANTA CATARINA, 1998, p. 36).

Na versão da Proposta Curricular de Santa Catarina: Estudos Temáticos (2005), que complementa o acervo de documentos de 1998, encontramos referência aos conceitos de alfabetização e letramento e uma direção assumida diante do debate que envolve estes dois temas:

[...] a difusão e o emprego do termo letramento passou a ter relevância no meio educacional, a partir da década de 1980. Traduz-se nas ações pedagógicas de reorganização do ensino, na reformulação e ressignificação dos novos modos de ensinar, ganhando espaço e credibilidade no discurso de teóricos, de especialistas e de professores/ alfabetizadores. Conjugar os conceitos de alfabetização e letramento, sem perder de vista a peculiaridade que caracteriza cada um deles, constitui desafio no processo de aprendizagem da língua portuguesa. (SANTA CATARINA, 2005, p. 23).

Há, portanto, o reconhecimento da especificidade dos conceitos de "aquisição da escrita" e "letramento" que se revelam com ênfase também na seguinte passagem:

O processo de aquisição da escrita, que demanda interaçóes específicas, acontece, normalmente, por meio da escolarização indispensável e fundamental a todo cidadão. Já o processo de letramento se efetiva ao longo da vida das pessoas, com a crescente participaçáo nas práticas sociais, nas quais circulam diferentes gêneros discursivos (SANTA CATARINA, 2005, p. 24). 
Nesse mesmo documento, encontramos também a retomada da compreensão da concepção de linguagem como interação, na perspectiva dos postulados histórico-culturais:
A linguagem não é um meio neutro através do qual uma mensagem é enviada. As palavras são carregadas de sentido para os falantes. A linguagem é, ela própria, criadora de significados e produtora de sentidos e como tal deve ser estudada. Segundo Bakhtin (1990), ela é inseparável do fluxo da interação verbal e, portanto, não é transmitida como um produto acabado, mas como algo que se constitui continuamente nessa corrente. (SANTA CATARINA, 2005, p. 22).

$\mathrm{Na}$ esteira dessa discussão, recorremos também ao que é assumido nos Parâmetros Curriculares Nacionais de Lingua Portuguesa (BRASIL, 2001, p. 24), que enfatizam:

[... a língua é um sistema de signos histórico e social que possibilita ao homem significar o mundo e a realidade. Assim, aprendê-la é aprender não só as palavras, mas também os seus significados culturais e, com eles, os modos pelos quais as pessoas do seu meio social entendem e interpretam a realidade e a si mesmas.

Com a implantação do ensino fundamental de nove anos, em 2007, o Ministério da Educação publica Ensino fundamental de nove anos: orientaçóes para a inclusão da criança de seis anos de idade no ensino fundamental (BEAUCHAMP; PAGEL; NASCIMENTO, 2007), documento que também trata da aprendizagem da leitura e da escrita focalizando relaçóes com o conceito de letramento. Seus autores enfatizam alguns aspectos importantes relacionados às questóes da alfabetização e do letramento, como, por exemplo, Goulart (2007, p. 93), que afirma:

Pode parecer banal, mas o primeiro conhecimento necessário para que se escreva é saber que se utilizam letras para escrever. Nem todas as crianças sabem disso quando chegam à escola. Depois saber que essas letras se organizam com base em convençôes, de acordo com 
um sistema de escrita de base alfabética. Aprendem que se escreve da esquerda para a direita e de cima para baixo. Aos poucos, as crianças vão observando diferentes padróes de sílaba e outras marcas diferentes de letras que aparecem nos textos (sinais de pontuaçáo, acentuação). Tudo isso precisa ser trabalhado de várias maneiras pelo (a) professor (a) com as crianças para que cada vez mais seus conhecimentos sobre a língua vão crescendo. [...] Para escrever, é preciso, também, ter um conhecimento textual: o modo como cada tipo de texto se organiza no papel, as diferentes características discursivas dos diversos tipos de textos (partes que os compóem, tempos verbais característicos etc.), informações relevantes, modos de iniciá-los, de terminá-los, entre tantas outras.

Percebe-se, portanto, que o conhecimento sobre a escrita não se restringe apenas à forma, a sua organização de texto como estrutura, mas relacionase intrinsecamente com a função social que desempenha cada gênero do discurso nas diversas esferas sociais e, por isso, aprender a ler e a escrever exige, certamente, conhecimentos relacionados à compreensão do próprio sistema de escrita, mas, simultaneamente, ao funcionamento social da língua, a sua condição dialógica. Argumenta Bakhtin (2003, p. 272):

Todo falante é por si mesmo um respondente em maior ou menor grau: porque ele náo é o primeiro falante, o primeiro a ter violado o eterno silêncio do universo, e pressupóe não só a existência do sistema da língua que usa mas também de alguns enunciados antecedentes - dos seus e alheios com os quais o seu enunciado entra nessas ou naquelas relaçóes (baseia-se neles, polemiza com eles, simplesmente os pressupóe já conhecidos do ouvinte). Cada enunciado é um elo na corrente complexamente organizada de outros enunciados.

De maneira geral, as propostas curriculares e documentos de orientação dirigidos a professores enfatizam a concepção de alfabetização na perspectiva do letramento e a concepção de linguagem como interação social. Cabe mencionar ainda neste círculo de aproximaçóes, políticas governamentais como os programas de formação específica para o professor Alfabetizador. O 
Pró-letramento e o Pacto Nacional pela Alfabetização na Idade Certa (PNAIC) ${ }^{4}$ se alinham a este plano de sentido: alfabetizar letrando. Ambos os programas governamentais atingiram nacionalmente um número expressivo de professores, assim como fomentaram o envolvimento de universidades e redes de ensino no que dizia respeito à responsabilidade sobre a formação docente. É oportuno destacar, todavia, que a formaçáo de profissionais em serviço desenvolvia-se sob a égide de um arcabouço teórico cujos princípios nem sempre eram congruentes entre si, dado que iam do construtivismo de base piagetiana à perspectiva histórico-cultural vigotskiana, muito embora a defesa era da concepção de linguagem como interação verbal, atribuindo ao sujeito que aprende a condição de ser de direitos que precisa se apropriar da leitura e da escrita para penetrar na arquitetônica do existir (mundo da cognição, da ética, da estética).

É o que salienta, por exemplo, o caderno do Ano 1, Unidade 1, do PNAIC (BRASIL, 2012, p. 22):

[...] defendemos que as crianças possam vivenciar, desde cedo, atividades que as levem a pensar sobre as características do nosso sistema de escrita, de forma reflexiva, lúdica, inseridas em atividades de leitura e escrita de diferentes textos. É importante considerar, no entanto, que a apropriaçáo da escrita alfabética não significa que o sujeito esteja alfabetizado. Essa é uma aprendizagem fundamental, mas para que os indivíduos possam ler e produzir textos com autonomia é necessário que eles consolidem as correspondências grafofônicas, ao mesmo tempo em que vivenciam atividades de leitura e produção de textos.

No caderno do PNAIC (BRASIL, 2012) são apresentados os objetivos da área de Língua Portuguesa aos quais subjaz a concepção de linguagem e de trabalho com a linguagem. Vejamos:

- Compreender e produzir textos orais e escritos de diferentes gêneros, veiculados em suportes textuais diversos, e para atender a diferentes propósitos comunicativos, considerando as condiçóes em que os discursos são criados e recebidos.

- Apreciar e compreender textos do universo literário 
(contos, fábulas, crônicas, poemas, dentre outros), levando-se em conta os fenômenos de fruição estética, de imaginação e de lirismo, assim como os múltiplos sentidos que o leitor pode produzir durante a leitura. - Apreciar e usar em situaçóes significativas os gêneros literários do patrimônio cultural da infância, como parlendas, cantigas, trava línguas.

- Compreender e produzir textos destinados à organização e socialização do saber escolar/científico (textos didáticos, notas de enciclopédia, verbetes, resumos, resenhas, dentre outros) e à organização do cotidiano escolar e não escolar (agendas, cronogramas, calendários, cadernos de notas...). - Participar de situaçóes de leitura/escuta e produção oral e escrita de textos destinados à reflexão e discussão acerca de temas sociais relevantes (notícias, reportagens, artigos de opiniāo, cartas de leitores, debates, documentários...). - Produzir e compreender textos orais e escritos com finalidades voltadas para a reflexão sobre valores e comportamentos sociais, planejando e participando de situaçóes de combate aos preconceitos e atitudes discriminatórias (preconceito racial, de gênero, preconceito a grupos sexuais, preconceito linguístico, dentre outros). (BRASIL, 2012, p. 32).

Esses encaminhamentos do PNAIC andam lado a lado com as discussóes amplas e profundas que se constituíram na década de com base na concepção histórico-cultural, cujos resultados fizeram surgir a defesa, sustentada ainda hoje, do o ensino dos usos sociais da língua em suas várias formas de manifestação, considerando-se os gêneros orais e escritos em seus diferentes propósitos comunicativos.

Em seu conjunto, os documentos oficiais aqui citados apontam para uma pedagogia da língua portuguesa que deva ser formulada com base em atividades de fala, escuta, leitura e escrita, cujo desenvolvimento importa ser acompanhado de análises e reflexóes sobre a língua. Logo, vislumbrar possibilidades metodológicas exige pensar sobre cada um desses eixos e como eles podem ser articulados entre si, quando se defende uma perspectiva de linguagem como interação humana,como bem enfatiza a Proposta Curricular de Santa Catarina (1998, p. 37): 
Faz-se necessária a discussão metodológica da prática alfabetizadora a partir de textos advindos de diferentes áreas do conhecimento. Estes deverão ser trabalhados, marcados pela interlocução do complexo de vozes dos autores, professores e alunos, que contribuem, apontam sutilezas e belezas, discutem, discordam, mas que efetivamente tornam-se co-autores no processo de apropriar-se da leitura e da escrita.

Assim, há de se considerar que a língua é dialógica, constituída nas relaçôes sociais e que, por isso mesmo, ela é necessária em todas as áreas do conhecimento. Como bem nos diz Bakhtin (2003, p. 319), "[...] qualquer estudo dos signos, seja qual for o sentido em que tenha avançado, começa obrigatoriamente pela compreensão [...]. Quando estudamos o homem, procuramos e encontramos signos em toda parte e nos empenhamos em interpretar o seu significado". Suas manifestaçôes ocorrem seja pela oralidade ou escrita (discursividade informal ou formalizada). As esferas sociais onde essas manifestaçóes se fazem necessárias é que determinarão o seu caráter, a sua forma de explicitação. Mesmo porque, "As unidades da comunicação discursiva - enunciados totais - são irreproduzíveis (ainda que se possa citá-las) e são ligadas entre si por relaçôes dialógicas" (BAKHTIN, 2003, p.335). Portanto, para o desenvolvimento do processo de escolarização cabe propor possibilidades metodológicas próximas das manifestaçóes discursivas que ocorrem no contexto social, para que os educandos compreendam a função social da fala, leitura e da escrita, como se manifestam, que aspectos merecem atenção no trato com o texto oral e escrito e em que circunstâncias se fazem presentes como "novo elo na cadeia histórica da comunicação discursiva” (BAKHTIN, 2003, p.311).

Por exemplo, em relação ao trabalho com a linguagem oral, os PCN apontam que:

Eleger a língua oral como conteúdo escolar exige o planejamento da ação pedagógica de forma a garantir, na sala de aula, atividades sistemáticas de fala, escuta e reflexão sobre a língua. São essas situaçôes que podem se converter em boas situaçóes de aprendizagem sobre os usos e as formas da língua oral: atividades de produção e interpretação de uma ampla variedade de textos orais, de observação de diferentes usos, de reflexão sobre os 
recursos que a língua oferece para alcançar diferentes finalidades comunicativas. Para isso, é necessário diversificar as situaçóes propostas tanto em relação ao tipo de assunto como em relação aos aspectos formais e ao tipo de atividade que demandam - fala, escuta e/ ou reflexão sobre a língua. Supóe também um profundo respeito pelas formas de expressão oral trazidas pelos alunos, de suas comunidades, e um grande empenho por ensinar-lhes o exercício da adequação aos contextos comunicativos, diante de diferentes interlocutores, a partir de intençóes de natureza diversa (BRASIL, 2001, p. 49-50).

Em relação à linguagem escrita, nesse mesmo documento se sustenta:

As pesquisas na área da aprendizagem da escrita, nos últimos vinte anos, têm provocado uma revolução na forma de compreender como esse conhecimento é construído. Hoje já se sabe que aprender a escrever envolve dois processos paralelos: compreender a natureza do sistema de escrita da língua - os aspectos notacionais e o funcionamento da linguagem que se usa para escrever - os aspectos discursivos; que é possível saber produzir textos sem saber grafá-los e é possível grafar sem saber produzir; que o domínio da linguagem escrita se adquire muito mais pela leitura do que pela própria escrita; que não se aprende a ortografia antes de se compreender o sistema alfabético de escrita; e a escrita não é o espelho da fala (BRASIL, 2001, p. 66).

Nessa perspectiva, aos estudantes devem ser oportunizadas possibilidades de contato com a escrita e com a leitura de textos diversos que circulam socialmente, desde seus primeiros momentos na escola, instigando-os a se debruçarem sobre essas escritas e leituras no intuito de provocar reflexóes e efetuar análises sobre a linguagem escrita, seus usos e formas, indo, portanto, ao encontro do último eixo abordado também nos PCN: o da análise e reflexão sobre a língua.

Vygotsky (2009) já anunciava a importância de se infundir na criança o desejo da escrita, bem como de auxiliá-la no domínio dos meios de fazê-lo. 
Obviamente que pensar em um trabalho metodológico nessa perspectiva significa defender uma concepção de linguagem em que se façam presentes conceitos tais como mediação e interação, próprios da abordagem históricocultural. Desse modo, o processo de aprendizagem ocorrerá por meio de um ensino sistemático e mediado por um "outro" mais experiente e conhecedor do objeto de aprendizagem, no caso, o professor, diante do objeto linguagem escrita. E para que essa relaçáo pedagógica se estabeleça faz-se necessário propiciar interaçóes diversas entre os estudantes e o objeto a ser ensinado, valorando a palavra dialógica, aquela constituída na arquitetônica textual e para fora dela.

Os Cadernos do Pacto Nacional pela Alfabetização na Idade Certa (PNAIC) (2012), em consonância com os Parâmetros Curriculares Nacionais (2001) e com as Orientaçóes para a Inclusão da Criança de Seis anos no Ensino Fundamental (2007), preconizam que é preciso organizar o trabalho pedagógico por meio de procedimentos, tais como sequências didáticas ou projetos didáticos, pois esses encaminhamentos favorecem uma atuação contextualizada e provocam situaçóes interdisciplinares, além de contribuírem para o trabalho com os eixos da língua portuguesa. Em um dos cadernos do PNAIC encontramos a seguinte afirmação:

Não é possível atuar isoladamente com conteúdos, sobretudo porque leitura e escrita são direitos de aprendizagem que, quando consolidados, desempenham o papel de sustentação de todo processo de ensino, já que as demais áreas do conhecimento exigem dos sujeitos o domínio das capacidades de ler e escrever de modo proficiente (BRASIL, 2012, p. 12).

Levar em conta a palavra dialógica significa considerar a linguagem como manifestação social, histórica e ideológica, um corpo vivo, enfim, que possibilita ao ser humano se situar em um tempo (histórico) e espaço (social) determinados, constituído e investido das vozes possíveis daquela organização social de que é partícipe. Não podemos, certamente, evocar a primazia de um trabalho com alfabetização que se centre, sobremaneira, nos aspectos grafofônicos destituídos da linguagem viva, e possível na sociedade, a qual expande a capacidade de formulação conceitual e comprometimento social pela responsividade e responsabilidade diante do dito ou do não dito (silêncio).

Assim, o ato de alfabetizar exigirá compreensão de conceitos da língua 
em sua complexidade, do sistema de escrita alfabética (ensino das letras, dos sons, das relaçóes entre estes, das regularidades e complexidades da linguagem escrita), da língua em suas diferentes modalidades (fala/escuta; leitura/escrita; análise linguística), do discurso (gêneros do discurso), entre outros, mas ocupando-se dos sentidos da língua em sua concretude interacional, dialógica e ideológica (refração). Como bem enfatizou Soares (2004), temos que atuar em nossas salas de aula trabalhando concomitantemente com os elementos gráficos e sonoros da escrita, reconhecendo que a compreensão da relaçáo fonemagrafema é crucial para a apropriação do sistema de escrita, mas sem descuidar dos aspectos discursivos. E, por certo, atentos ao desenvolvimento da atividade de aprendizagem, especialmente aos sentidos de cada uma das formulaçóes, provindas de açóes reais de ambos os interactantes, professores e estudantes. Nessa perspectiva, são bem-vindos jogos, brincadeiras, rimas, associaçôes diversas, atividades lúdicas de modo geral, com textos que circulam socialmente, inseridos em projetos de docência que possam alfabetizar, edificando o processo alfabetizador mediante a unidade real da comunicação verbal, qual seja, a palavra real como enunciado concreto. Afinal, "Todo enunciado concreto é um elo na cadeia da comunicaçáo discursiva de um determinado campo. [...] Os enunciados não são indiferentes entre si nem se bastam cada um a si mesmos; uns conhecem os outros e se refletem mutuamente uns nos outros" (BAKHTIN, 2003, p. 297).

\section{Considerações finais}

A alfabetização do ponto de vista da perspectiva histórico-cultural leva à defesa de uma metodologia de alfabetizaçáo que consolide o processo de ensino e aprendizagem centrado nas práticas sociais de leitura e escrita, considerando assim a importância da apropriação do sistema de escrita em contextos de valoração dos sujeitos com responsabilidade sobre o pensar, falar e atuar.

Portanto, urge reforçar políticas de formação em serviço para professores alfabetizadores que possam considerá-los em sua real necessidade no cuidado com seus interlocutores, com o objeto do seu ensino, visando atitudes responsivas no fazer da pedagogia da língua arquitetada para formação de leitores e escritores competentes. Assim, o caminho que defendemos não é a mera instrumentalização de métodos como foi outrora, mas de investimento em reflexôes profundas sobre a linguagem em suas multiplicidades e atitudes, 
para que as crianças venham compreender, se apropriar e aprofundar esse conhecimento que é linguagem humana. Discussão, diga-se, não nova, porém atentos ao nosso tempo, ainda necessária, neste momento em que a infância se constitui em um ambiente multissemiótico, justificando os desafiadores "mundo das coisas" e "mundo dos sentidos" em suas controversas aproximaçóes e distanciamentos. Métodos de alfabetização, com passos didático-metodológicos nem sempre flexíveis que haviam abandonado o cenário educacional há décadas retornam e podem até retornar como solução para a desafiante ação de alfabetizar. Contudo, é oportuno ressalvar, a importância de olhar para o passado, com a memória do passado e do que foi o futuro desse passado (nosso presente), para, então, constituirmos, apoiados em reflexóes e políticas públicas consistentes, rumos que justifiquem esse retorno como coadjuvante na construção do conhecimento e na compreensão do diálogo que constrói a minha palavra, a palavra do outro, sobressaindo, na arquitetônica dos enunciados, sinais mais visíveis do "mundo da cognição", da apropriação da língua como sistema, sim, mas lado a lado com o desenvolvimento da língua/linguagem como interação humana.

\section{Notas}

${ }^{1}$ Tanto o Pró-Letramento quanto o Pacto Nacional pela Alfabetização na Idade Certa (PNAIC) são programas oriundos do governo federal voltados para a formação de professores alfabetizadores, implementados mediante adesão ao programa por parte das universidades públicas, em parceria com estados e municípios.

${ }^{2}$ Sobre "alfabetização" e "letramento" e respectivos enfoques, consulte, por exemplo, Soares (2006, 2008); Tfouni (2002); Rojo (2006); Vóvio, Sito e Grande (2010).

${ }^{3}$ Cabe ressaltar que a Secretaria de Educação do Estado de Santa Catarina, desde a formulação de sua Proposta Curricular no ano de 1998, iniciou cursos de formação continuada. Em 2014 foram efetuadas discussóes, com vistas a atualização desses cursos de formação.

${ }^{4}$ Informação e material sobre ambos os programas estão disponíveis em: $<$ http://portal.mec.gov.br/index.php?option=com_content\&view=artic le\&id=18838\&Itemid $=842>$. 


\section{REFERÊNCIAS}

BEAUCHAMP, Jeanete; PAGEL, Sandra Denise; NASCIMENTO, Aricélia Ribeiro do (Org.). Ensino fundamental de nove anos: orientações para a inclusão da criança de seis anos de idade. Brasília: MEC/SEB, 2007. Disponível em: <http://portal.mec.gov.br/seb/arquivos/pdf/Ensfund/ ensifund9anobasefinal.pdf>. Acesso em: jan. 2011.

BAKHTIN, Mikhail [Volochínov]. Marxismo e flosofia da linguagem: problemas fundamentais do método sociológico na ciência da linguagem. 5. ed. São Paulo: Hucitec, 1990.

BAKHTIN, Mikhail. Estética da criação verbal. Tradução de Paulo Bezerra. 4. ed. São Paulo: Martins Fontes, 2003. (Coleção Biblioteca Universal). BRASIL. Ministério da Educação. Secretaria da Educação Fundamental. Parâmetros Curriculares Nacionais: Língua Portuguesa. 3. ed. Brasília, DF: MEC/SEB, 2001.

BRASIL. Ministério da Educação. Secretaria de Educação Básica. Diretoria de Apoio à Gestão Educacional. Pacto Nacional pela Alfabetização na Idade Certa: currículo na alfabetização: concepções e princípios. Brasília: MEC/ SEB, 2012.

GOULART, Cecília. A organização do trabalho pedagógico: alfabetização e letramento como eixos orientadores. In: BEAUCHAMP, Jeanete; PAGEL, Sandra Denise; NASCIMENTO, Aricélia Ribeiro do (Org.). Ensino fundamental de nove anos: orientaçóes para a inclusão da criança de seis anos de idade. Brasília: MEC/SEB, 2007. p. 85-95. Disponível em: <http:// portal.mec.gov.br/seb/arquivos/pdf/Ensfund/ensifund9anobasefinal.pdf >. Acesso em: jan. 2011.

SANTA CATARINA. Secretaria de Estado da Educação e do Desporto. Proposta Curricular de Santa Catarina: Educação Infantil, Ensino Fundamental e Médio: Disciplinas curriculares. Florianópolis, SC: COGEN, 1998.

SANTA CATARINA. Secretaria de Estado da Educação, Ciência e Tecnologia. Proposta Curricular de Santa Catarina: estudos temáticos. Florianópolis, SC: IOESC, 2005. 
ROJO, Roxane (Org.). Alfabetização e Letramento: perspectivas linguísticas. Campinas, SP: Mercado de Letras, 1998.

SOARES, Magda. Letramento e alfabetização: as muitas facetas. Revista Brasileira de Educação, Rio de Janeiro, n. 25, jan./abr. 2004. Disponível em: <http://www.scielo.br/scielo.php?script=sci_arttext\&pid=S141324782004000100002\&lng=pt\&nrm=iso Acesso: 20 de abr. 2014>.

SOARES, Magda. Letramento: um tema em três gêneros, 2. ed. Belo Horizonte: Autêntica, 2006.

SOARES, Magda. Alfabetização e letramento. 5. ed. São Paulo: Contexto, 2008.

TFOUNI, Leda V. Letramento e Alfabetização. 4. ed. São Paulo:Cortez, 2002. (Coleção Questôes da Nossa Época).

VÓVIO, Cláudia Lemos; SITO, Luanda; GRANDE, Paula Baracat de (Org.). Letramentos: rupturas, deslocamentos e repercussóes de pesquisas em linguística aplicada. Campinas, SP: Mercado de Letras, 2010.

VYGOTSKY, Lev Semenovitch. A imaginação e a arte na infância. Tradução de Miguel Serras Pereira. Portugal: Relógio D’Água, 2009. 


\section{L'alphabétisation et le dialogisme: rencontres avec la parole dan la vie}

\section{Résumé}

Dans ce travail, on cherche de contextualiser l'importance pour l'alphabétisation de la conception dialogique du langage l'architectonique de Bakhtin -, et de la perspective d'apprentissage de Vigotski, en cherchant de contribuer avec les discussions qui s'y posent depuis les anées 1980 jusqu' à aujourd'hui. À cet effet, sont présentées, en lignes générales, les orientations des documents officiels dans ce qui concerne aux conceptions du langage et aux propostes théoriqueméthodologiques dans une perspective de lettrement et d'intération sociale. On fait aussi la défense de l'alphabétisation à travers l'approche historique-culturel et des pratiques sociales de lecture et écrite constituées dans le rapport je/l'autre. On discute encore quelques possibilités méthodologiques développées sur des projets d'enseignement qui puisse édifier le processus d'alphabétisation par l'activité de la communication verbale, c'ést à dire, par la parole reél comme énoncé concret. Pour la fin, on défendent la consolidation d'une méthodologie de l'alphabétisation qui favorise le développement de pratiques sociales pendent le processus de l'appropriation du système de l'écriture, au même temps que conduit à valorisation du sujet résponsable de la pensée, du parler et de l'agir. On recommend, ainsi, le

\section{Literacy and dialogism: meetings with the word in life}

\section{Abstract}

In this work we tried to contextualize the importance for literacy dialogical conception of language - the architectural Bakhtin - and Vygotsky's learning perspective, seeking to contribute to discussions on the subject that have been put through since the 1980s until the present day. For such purpose, the guidelines of the official documents with regard to language concepts and theoretical and methodological proposals in a perspective of literacy and social interaction are presented in a general aspect. This paper also makes the defense of literacy by the historical-cultural approach and social practices of reading and writing that are constituted in the relationship self / other. We also discuss some methodological possibilities that are developed based on teaching projects that can build the literacy process by the verbal communication activity, i.e .the real word as a concrete enunciation. Finally, it advocates the consolidation of a methodology of literacy which encourages the development of social practices in the course of the writing system appropriation process, as well as a methodology that can lead to the valuation of the subject with responsibility for thinking, speaking and acting.

Keywords: Literacy. Verbal interaction. Teacher training. 
renfort de politiques públiques de formation de professeurs dans le travail, en stimulant des attitudes responsables devant les sujetsétudiants, en leur formant de lecteurs et d'écrivains compétents.

Mots-clés: Alphabétisation. Interactions verbale. Formation d'enseignant.

Maria Aparecida Lapa de Aguiar

E-mail: lapa.aguiar@ufsc.br

\section{Nelita Bortolotto}

E-mail:nelita.bortolotto@ufsc.br

\section{Nilcéa Lemos Pelandré}

E-mail: nilcea.pelandre@ufsc.br

Enviado em: 13/7/2014 Aprovado em: 28/11/2014 